\title{
The Role of Regional Science in Migration and Population Research
}

\author{
David A. Plane*
}

Abstract: This article considers regional science's role in contributing to migration research, and population research more generally. Beyond the intrinsic appeal of regional science's systems approach, migration analysis was one of our multidisciplinary field's success stories from the late 1960s through the early 1980s because of a widespread production of results that were of inherent interest, that were in some cases controversial, and that were successful in provoking policy discussions. My main argument is that we experience the validation of our belief in the importance of analytical, theory-driven perspectives on the world when the theoretical expertise and analytical rigor of regional science methods can be brought to bear on real-world empirical issues. Consequently, I argue that we should make population analysis an important, foundational element in regional science training.

\section{MIGRATION ANALYSIS: A REGIONAL SCIENCE "SUCCESS STORY"}

Recently, a collaborator and I completed an analysis of the role of migration research in regional science (Plane and Bitter 1997). That study disclosed that migration studies (and population research more broadly) have been a small but important component of the literature published in five leading regional science journals. In this article I do not focus so much on the role of migration and population research in regional science. Rather, I examine regional science's role to date, and potential role in the future, in contributing to knowledge about population distribution and population change-and, in particular, the migration component of population change.

One of the findings of the earlier study was that migration and population papers grew from only 3.6 and 4.6 percent of all papers in the journals surveyed during the period 1955-59 to a peak of 9.5 and 7.7 percent during $1980-84$. Since then, there has been a bit of a decline-to 6.8 and 3.5 percent for 1990-94 (when our study period concluded).

In thinking about the future and about the significance of regional science to migration and population we can ask what was it that contributed to this growing production of knowledge during the decades leading up to the early 1980s? Several factors were probably working in conjunction; these could perhaps be instructive to us in thinking about how to increase the impact of regional science scholarship more generally. One of these factors is that regional science, during the later 1960 s and the 1970 s, was a major contributor to the then quite widespread interest in empirical modeling. Analyses of the determinants of migration 
using econometric techniques produced results that were of inherent interest, that were in some cases controversial, and that were successful in provoking policy discussions. As my colleague Gordon Mulligan has noted, the elegance of linking economic and demographic accounting frameworks using sound theoretical constructs captured many of our imaginations. Its successful application provided strong validation of the systems perspective that Isard (1960) had been extolling so vigorously as a main virtue of the regional science approach.

Another factor is that regional scientists were very much involved in trying to explain the empirical trends then underway. In particular, the "metro/nonmetro turnaround" phenomenon of the 1970s (that nonmetropolitan areas were suddenly growing faster, on balance, than metropolitan regions) captured the popular as well as the academic imagination. Regional scientists, with their wellhoned analytical skills, were in the forefront of the debates about what the data were really showing and what the underlying causes of such trends might in be. I think the metro/nonmetro turnaround was such a significant event for regional science because the focus on nonmetropolitan areas involved both scholars and the large policy communities concerned with rural areas. The strong linkage among the academic field of agricultural economics, federal agencies involved in regional policy (e.g., USDA and BEA), and U.S. regional science organizationsan academic/governmental complex nowhere stronger than in the Southern Regional Science Association-made this a prime topic for regional scientists to pursue and one in which they could leave their mark on a wide body of literature and public debate.

\section{THEORETICAL VERSUS APPLIED: A FALSE POLARIZATION}

For me, some of the recent debate over the future of regional science represents a false polarization between the intrinsic value of "theoretical" versus "applied" work. It has been said that an academic is someone with a congenital inability to distinguish between "quality" and "what I do." Most scholars are inclined to one mode of research, but in my opinion it is in circumstances such as those just discussed where we see some real impacts accruing to our regional science enterprise. It is when the theoretical expertise and analytical rigor of regional science methods can be brought to bear on real-world empirical issues that we experience the validation of our belief in the importance of analytical, theorydriven perspectives on the world. ${ }^{1}$

In my experience, when we eggheads are asked to provide our thoughts on future directions for research in a particular subfield we generally take the bait. We pull out of the pond and hold up for admiration some dripping wet piece of work that has recently caught our fancy. Most of us, if we are to have successful careers, must have some sense of how to steer our own research agendas into productive waters. But few of us are adept at perceiving trends and opportunities that lie outside the narrow streams and eddies within which we carry out our own studies.

${ }^{1}$ Rogerson (1995) makes a somewhat similar argument. 
Twice in the past I have been asked to compose my thoughts about the future of migration research in regional science. One of those occasions was during Michael Greenwood's year as President of the Western Regional Science Association. In lieu of publishing the traditional Presidential Address, he used the opportunity to coauthor with several of us a forward-looking piece about those topics and methods in migration research that we felt provided some of the best opportunities for future advances (see Greenwood et al. 1991). Although some good ideas were explored in that paper in a rather more in-depth fashion than is typical of such "thought" pieces, the effort was by no means a comprehensive attempt to organize all the migration work needing to be done by regional scientists.

A somewhat more proscriptive effort to suggest general tendencies and directions may be found in "The Ten Commandments of Migration Research," originally presented at the 3rd World Congress of the Regional Science Association International (RSAI) in Jerusalem (Plane and Rogerson 1991). Codified in that piece are many of the areas that I continue to think need more attention by regional science migration specialists. While some progress has been made, there are still plenty of opportunities not yet seized. For instance one of those "commandments" called for more attention to be paid to international immigration. However, the recent classification of regional science journal literature (Plane and Bitter 1997) does not disclose for the early 1990s any significant increase in publication on immigration topics within regional science. That finding is in sharp contrast to the trend in American population geography, where international migration has become the most prevalent topic of current research studies-with many of those studies using regional science-type models (hazard functions, multinomial logit formulations, and so forth).

\section{REGIONAL SCIENCE TRAINING}

One of the recent broad trends in regional science has been the increased attention paid to educational curricula and to teaching. Here I think that there is an interesting contrast between the education being given to economics-trained regional scientists and to regional science-oriented students in geography and planning programs. Population and migration are not central to the curriculum in the former case, but are much more so in the latter case. ${ }^{2}$

A few years ago at the North American Meetings of the RSAI, Walter Isard held a special plenary session to discuss the revised outline for the then forthcoming second edition of Methods of Regional Analysis (Isard et al. 1997). I remarked during my panelist presentation that the outline looked quite a bit like that of the first edition (Isard 1960), with the main exception being that the original book's first two substantive chapters were on population projection and migration estimation, whereas the second edition would drop population while retaining only some perspectives on migration. I argued that there should be

${ }^{2}$ For an interpretation of how the home disciplines of scholars affect their participation in regional science see Plane (1994). 
more, not less attention paid to population. In the words of Hägerstrand (1970): "What about people in regional science?"

Last fall three of the regional science members of my geography department began offering a large (700 to 1,000 students per semester) introductory course for the University of Arizona's new freshman year General Education Curriculum. The three modules we teach are on (a) population systems, (b) urban systems, and (c) economic systems. We consider population distribution and population processes foundational materials for the teaching of human geographyand for the "individuals and societies" interdisciplinary area that the course is intended to survey. In most any version of introductory micro- or macroeconomics, however, population and migration are probably given at most a passing reference. Isard's contention in dropping the population projections and estimates section of his book was that these chapters were little used and that most all population research in regional science has been on migration. While this may well be, I find it interesting that since the first edition has appeared a whole new industry of applied demographic analysis has sprung up. There are now significant job markets in marketing and planning where regional science-trained students would have a real competitive advantage. Yet we offer little in the way of training in applied demographic analysis. The regional scientist's skills would doubtless make for much better, more theoretically defensible demographic analysis and GIS-based methods. While some interchange takes place at regional science conferences and in regional science journals about transportation and GIS, virtually nothing can be found in our migration/population group. ${ }^{3}$

\section{CONCLUSIONS}

Population research and regional science are both multidisciplinary realms of study. Within regional science, migration research has perhaps overly dominated the population-oriented research. There is no reason why regional scientists aren't equipped to make major contributions to, for instance, fertility analysis. Yet only once in a blue moon does the editor of a regional science journal receive a submission about regional trends or patterns of births. Perhaps it has been because migration is a relatively neglected branch of demography that regional science's impacts have been significant despite our small number of contributing scholars.

In any multidisciplinary enterprise it is important to have some core topics or methods that rally a group of specialists. The topics and methods that captured our fancies in the 1950s and 1960s may now, at the end of the 1990s, seem overstudied and less interesting than they were forty years ago. I have argued that during the 1970s and early 1980s a conjunction of events brought migration research into the center ring of the regional science arena. In the years ahead, similar opportunities should present themselves for population topics and methods

3 One attempt to treat in a single book a broad spectrum of applied geographical methods for population analysis is Plane and Rogerson (1994). 
to be advanced through regional scientists' efforts. Demographics inherently affect economic and social systems.

Seizing opportunities must necessarily be a somewhat spontaneous activity, and one that may be inherently unplannable. We cannot with any precision predict what the exciting regional trends and policy areas will be in the decades ahead. But I would bet that the realm of population analysis will continue to present us with prime opportunities to display the intrinsic value of a theory-based regional science approach to trying to understand significant societal trends. After all, one of the only true laws of social science may be that most of us get older, one year at a time. So I believe that one way we can make an investment in promoting better, more relevant, and more visible regional science scholarship is in agreeing to make population analysis an important, foundational element in regional science training. Regional scientists early on caught on to the importance of economicdemographic linkages. I think it is time we tried to make that linkage more explicit in our curricula and individual courses.

\section{REFERENCES}

Greenwood, Michael J., Peter R. Mueser, David A. Plane, and Alan M. Schlottmann. "New Directions in Migration Research: Perspectives from Some Regional Science Disciplines." The Annals of Regional Science 25 (1991), 237-270.

Hägerstrand, Torsten. "What About People in Regional Science?" Papers of the Regional Science Association 66 (1970), 1-6.

Isard, Walter. Methods of Regional Analysis. Cambridge, MA: MIT Press, 1960.

Isard, Walter, Ronald E. Miller, Sidney Saltzman, Erik Thorbecke, Iwan Aziz, and Matthew P. Drennen. Methods of Interregional and Regional Analysis. Brookfield, VT: Ashgate Publishers, 1997.

Plane, David A. "Comment: On Discipline and Disciplines in Regional Science." Papers in Regional Science: The Journal of the Regional Science Association International 73 (1994), 19-23.

Plane, David A., and Christopher Bitter. "The Role of Migration Research in Regional Science." Papers in Regional Science: The Journal of the Regional Science Association International 76 (1997), 133-153.

Plane, David A., and Peter A. Rogerson. "The Ten Commandments of Migration Research." In David E. Boyce, Peter Nijkamp, and Daniel Shefer (eds.) Regional Science: Retrospect and Prospect, 15-42. Berlin: Springer-Verlag, 1991.

. The Geographical Analysis of Population: With Applications to Planning and Business. New York: John Wiley \& Sons, 1994.

Rogerson, Peter A. "Regional Science: A Question of Balance." International Regional Science Review 18 (1995), 219-222. 
